\title{
Investigation of the Influence of the Space Orientation of Layers on the Surface Shape Error during Additive Shaping of Products by an Electric Arc in a Protective Gases Environment
}

\author{
Aleksandr Grechukhin ${ }^{1, *}$ and Vadim Kuts ${ }^{1}$ \\ ${ }^{1}$ Southwest State University, 50 Years of October St., 94, Kursk, Russia
}

\begin{abstract}
The paper presents the results of a study of the process of additive surface shaping by an electric arc in a protective gas. An analysis was made of the errors in the shape of surfaces obtained with different filling of layers. It has been experimentally confirmed that such process parameters as the orientation of the layers, the coefficient of their overlap are significant and affect the numerical value of the error in the shape of the resulting surface. In this connection, they should be taken into account when designing algorithms for dividing into layers and filling them with additive shaping by an electric arc in a protective gas.
\end{abstract}

\section{Introduction}

Additive technologies are increasingly being used in almost all areas of industry. Their use in some operations of the technological process of manufacturing products, allows you to achieve a significant economic effect. The expansion of the field of application of additive technologies has become possible due to the development of new methods that implement the technology of additive shaping using various construction materials, as well as various energy sources [1-4].

One of the varieties of the above technology is the technology of electric arc additive growing, with the involvement of methods of arc welding with a consumable electrode in a shielding gas. These methods have significant energy efficiency and high productivity. For example, some MIG welding methods can be up to $90 \%$ energy efficient [6]. Methods of additive wire shaping have a number of common features: the presence of residual stresses and deformation of the product, relatively low manufacturing accuracy. Nevertheless, the above methods are actively developing. A large number of publications are devoted to the problems of additive manufacturing based on electric arc welding technology. One of them [5-7] is the problem of forming the structure of the metal of the rollers being deposited. Another problem is to ensure the accuracy of the geometry of the products formed by the deposited rollers [8]. This may be due to the fact that the area of the previous layers is exposed to significant heating. This fact may be associated with some deterioration in the relative elongation of the geometry of the resulting products. In this case, a change in the

* Corresponding author: agrechunin@mail.ru 
geometry of the deposited layers can be observed with an increase in the height of the deposited product.

The study is devoted to the study of the accuracy of the surface of products formed by fusing a building material with an electric arc in a protective gas.

The questions [13] of the formation of errors during machining were investigated in the work. In it, the processing error was considered as a result of the action of the corresponding components:

$$
\Delta r_{0}=\Delta r_{\mathrm{st}}+\Delta r_{\mathrm{dyn}}+\Delta r_{\mathrm{tem}}+\Delta r_{\mathrm{t} . \mathrm{wear}}+\Delta r_{\mathrm{w} . \text { parts }}
$$

where $\Delta r_{\text {st }}$ - static component of processing error; $\Delta r_{\text {dyn }}-$ dynamic component of processing error; $\Delta r_{\text {tem }}$ and $\Delta r_{\text {t.wear }}$ - errors caused by temperature deformations and tool wear, respectively; $\Delta r_{\text {w.parts }}$ - error caused by wear of parts of assemblies.

It should be noted that the shaping of parts by the method of welding with an electric arc in a protective gas, like most methods of additive shaping, is characterized by high values of the static component of the processing error, which, in general form, can be represented in the form of the equation $[14,15]$ :

$$
\Delta_{r}=\Delta_{r_{1}}+\Delta_{r_{2}}
$$

where $\Delta_{r_{1}}$ - position error, $\Delta_{r_{2}}$ - form error.

Figure 1 presents a diagram of the formation of the static component of the error of additive shaping by an electric arc in a protective gas environment using different orientations of the deposited layers.

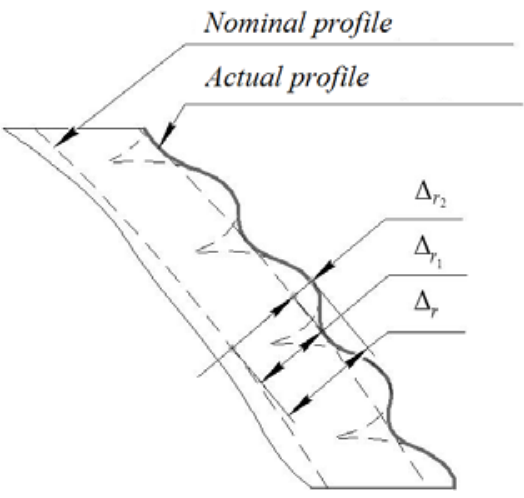

a)

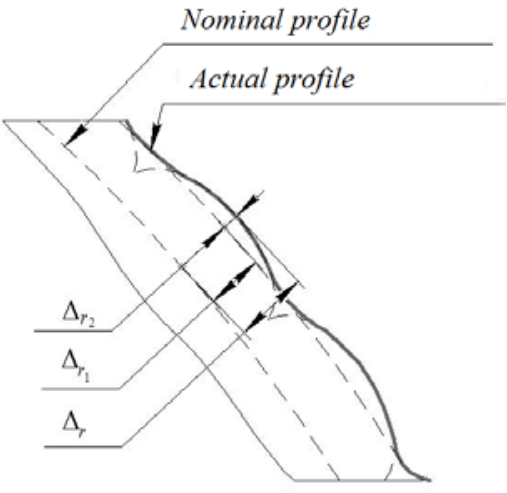

b)

Fig. 1. The diagram of the formation of an error is presented when forming products by additive methods: a) the formation of layers is carried out in the vertical direction; b) the formation of layers is carried out in the horizontal direction; $\Delta_{r}$ - total error, $\Delta_{r_{1}}$ - position error, $\Delta_{r_{2}}$ - form error.

There were published works [9-12], in which, as a result of theoretical studies, it was indicated that one of the measures to reduce the error in the shape of additive methods of shaping can be a change in the spatial orientation of the deposited layers. However, they do 
not represent information from experimental studies that confirm or refute the results obtained. Therefore, an urgent task of the presented study is to conduct experiments aimed at establishing the effect of changing the spatial orientation of single deposited layers on the shape error of the resulting products.

It is also of interest to study the effect of the layer overlap coefficient on the error of additive shaping by an electric arc in a shielding gas environment, deposited in parallel.

Experimental studies were carried out to solve the indicated problems.

\section{Research technique}

The laboratory bench was created, consisting of a vertical milling machine with numerical control model 07N25PF2, which implements the movement of the desktop along 3 coordinate axes. It allows to partially automate the process of fixed deposition. The semiautomatic welding machine was used as an energy source for an inverter-type electric arc of the Kedr model MIG-160GDM MIG / MAG, MMA with an internal wire feed system.

The implementation of the process of volumetric electric arc surfacing included the following stages: development of a model of single layers to be deposited - it was carried out using the specialized program KOMPAS-3D V17.1; setting the trajectory of movement of the machine tool actuators - it is carried out using specialized software.

Welding was carried out on a prepared substrate fixed on the machine table in a semiautomatic mode using a semi-automatic welding machine. The holder was made to secure the welding torch. The holder was made to secure the welding torch. The welding head nozzle was located relative to the workpiece surface. Wire made of 09G2S steel with a diameter of $0.8 \mathrm{~mm}$ was used as a building material.

The following schemes of deposition of single layers were implemented:

1. The layer is attached to the layer on a horizontal surface with an overlap ratio of 0.3 ;

2. The layer is attached to the layer on a horizontal surface with an overlap ratio of 0.5 ;

3. The layer is applied to the layer in the vertical direction.

Fusion was carried out in a mixture of argon and carbon dioxide in a ratio of $12 / 88 \%$. The modes of the deposition process were: the speed of movement of the welding torch 150 $\mathrm{mm} / \mathrm{min}$; construction material feed rate - from $3.1 \mathrm{~m} / \mathrm{min}$; arc voltage - 17 volts.

Figure 2 shows deposited specimens.

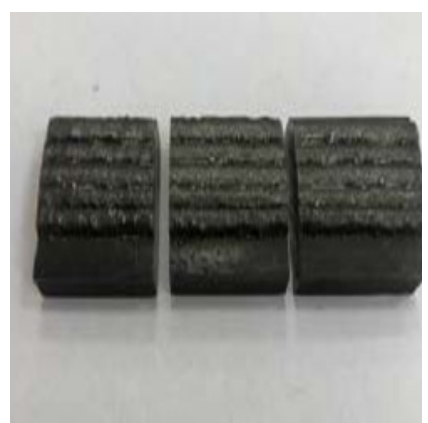

a)

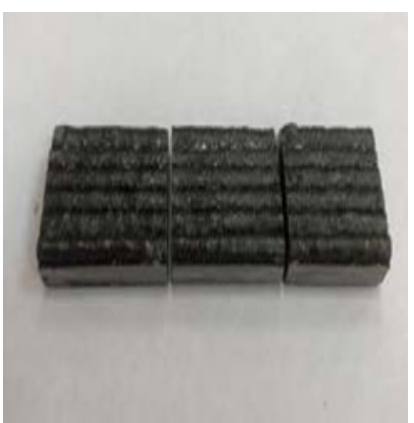

b)

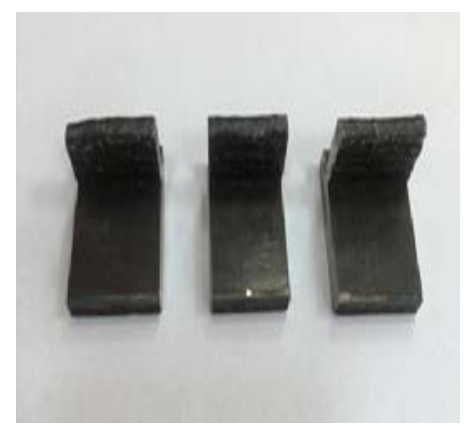

c)

Fig. 2. Experimental samples are represented by single layers, deposited in various ways: the layer is applied to the layer in the vertical direction; b) the layer is attached to the layer on a horizontal surface with an overlap ratio of 0.3 ; c) the layer is attached to the layer on a horizontal surface with an overlap factor of 0.5 . 
The measurement was made for the shape error of the obtained sample. A small instrumental microscope was used to measure the shape error of the obtained samples. Measurements were made in 3 sections at 24 points of each of the manufactured samples.

\section{Research results and their analysis}

The results of measuring the shape error are presented in Figure 3 in the form of a bar chart. Thus, the error in the formation of samples of surfacing layer-by-layer in the vertical direction turned out to be higher in comparison with other surfacing methods implemented in the experiment. The average values of the sample shape error are $0.75 \mathrm{~mm}, 0.88 \mathrm{~mm}$, $1.15 \mathrm{~mm}$, respectively, for methods of surfacing layer-to-layer on a horizontal surface with an overlap ratio of 0.3 , layer-to-layer on a horizontal surface with an overlap ratio of 0.5 , layer by layer in the vertical direction. The maximum error values are determined at the level of $0.85 \mathrm{~mm}, 1.2 \mathrm{~mm}, 1.5 \mathrm{~mm}$ for the corresponding surfacing methods implemented in the experiment.

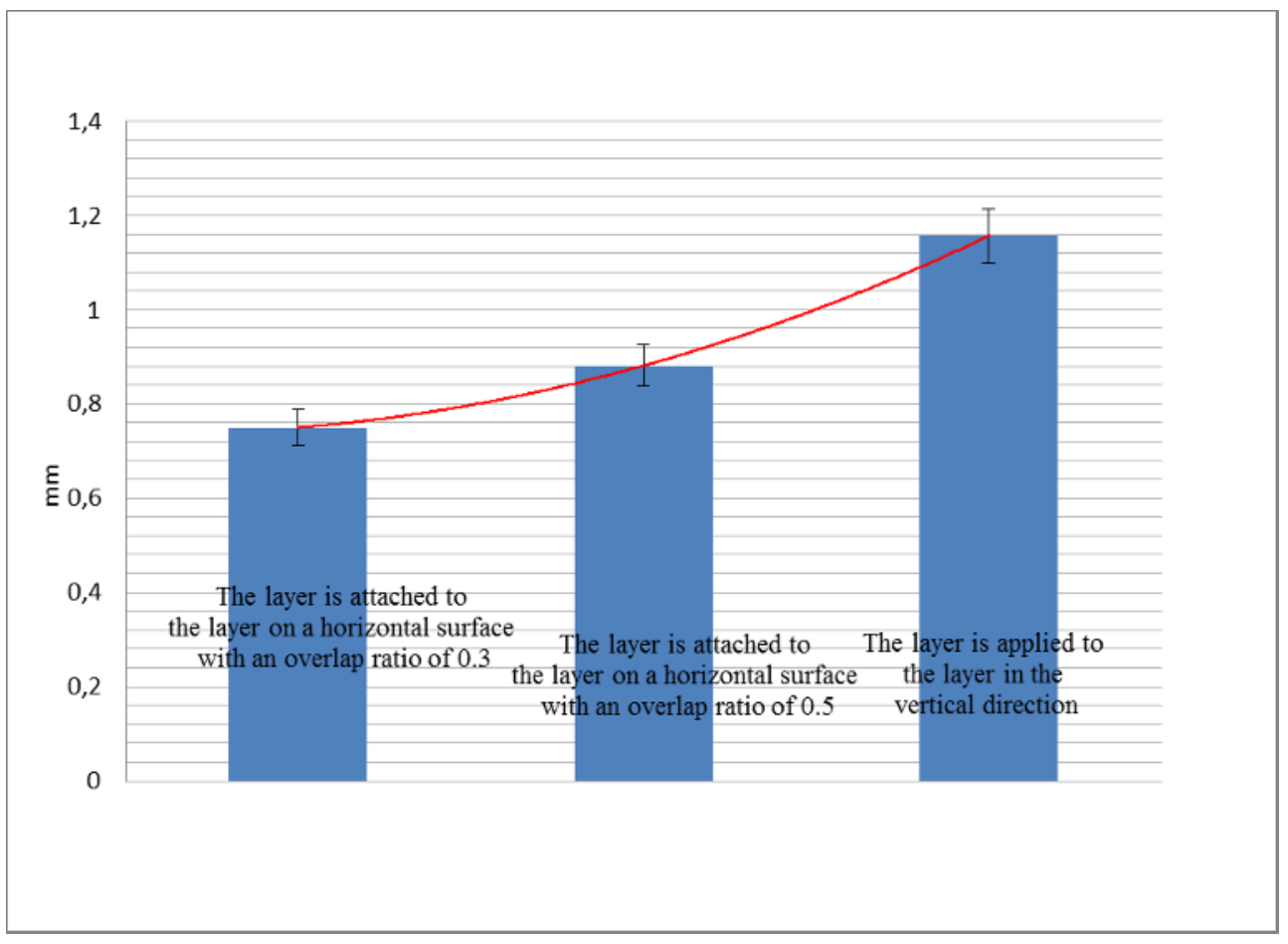

Fig. 3. Diagrams show the results of measuring the shape error.

To confirm the significance of the factors of changing the spatial orientation of the layers, as well as the coefficient of overlap of layers in the process of additive shaping of products by an electric arc in a protective gas, a two-factor analysis of variance was carried out. The analysis results confirm the results of the experiments carried out. This indicates that the spatial orientation of the layers and the coefficient of overlap of layers are significant parameters for controlling the shaping error, and therefore they should be taken into account when forming surfaces by layer-by-layer electric arc surfacing with an electric arc in a shielding gas environment. 
Influence has a significant effect on the accuracy of electric arc methods of additive shaping, deposition modes.

Therefore, an urgent task is to identify the dependences of the influence of the modes of electric arc surfacing on the parameters of the rollers being deposited. And on the basis of the revealed dependencies, the development of a comprehensive methodology for controlling the accuracy of additive shaping by an electric arc in a protective gas environment should be carried out.

\section{Conclusion}

The space orientation of the deposited layer, as well as the overlap ratio of the deposited layers, influence the value of the form error during the formation of surfaces by additive welding with an electric arc in a shielding gas environment. Of interest for further research is obtaining regression models of the influence of the parameters of the process of additive shaping by an electric arc in a protective gas environment on the form error of the resulting surfaces.

The study was supported by the scholarships of the President of the Russian Federation for young scientists and postgraduates SP-4738.2021.1

\section{References}

1. Dave V. R. Electron beam solid freeform fabrication of metal parts / V. R. Dave, J. E. Matz, T.W. Eagar // Proceedings of the Solid Freeform Fabrication Symposium, Austin, USA. - 1995. - P. 64-70. - access mode: http://sffsymposium. engr.utexas.edu/Manuscripts/1995/1995-09-Dave.pdf

2. Friel R. J. Ultrasonic additive manufacturing - a hybrid production process for novel functional products / R. J. Friel, R. A. Harris // Proceedings of the Seventeenth CIRP Conference on Electro Physical and Chemical Machining (ISEM). - 2013. - Vol. 6. P. 35-40. - access mode: http://www.sciencedirect. com/science/article/pii/S2212827113000784

3. Dickens P. M. Rapid prototyping using 3-D welding / P. M. Dickens, M. S. Pridham, R. C. Cobb, I. Gibson, G. Dixon // Proceedings of the Solid Freeform Fabrication Symposium, Austin, USA. - 1992. - P. 280-290. - access mode: http:// sffsymposium.engr.utexas.edu/Manuscripts/1992/1992-32- Dickens.pdf

4. Burns M 1993 Automated Fabrication: Improving Productivity in Manufacturing (Englewood Cliffs. N.J. USA: PTR Prentice Hall) 369 pp.

5. Saprykin A A 2006 Increasing the productivity of the process of selective laser sintering in the manufacture of prototypes Thesis of candidate of technical Sciences (Yurga: Tomsk Polytechnic University) p 153.

6. Pronikov A, Averyanov O I and Apollo Yu S 1994 Designing of metal-cutting machines and machine tools (Handbook-textbook vol 3) (Moscow: MSTU them NE Bauman: Mechanical Engineering) p 444.

7. Kuts V V, Razumov M S, Grechukhin A N and Bychkova N A 2016 Improving the quality of additive methods for forming the surfaces of odd-shaped parts with the application of parallel kinematics mechanisms. International Journal of Applied Engineering Research 11 pp 11832-11835. 
8. Singhal S K, Pandey A P, Pandey P M and Nagpal A K 2005 Optimum part deposition orientation in stereolithography Computer-Aided Design \& Applications 2 pp 319328.

9. Hong S, Byun Kwan H Lee 2004 Optimal part orientation of rapid prototyping using a genetic algorithm. Computers \& Industrial Engineering pp 426-431.

10. Lan P T, Chou S, Chent Y, Gemmill L D 1997 Determining fabrication orientations for rapid prototyping with stereolithography apparatus. Computer-Aided Design 29 pp 5362.

11. Massod S H, Rattanawong W Iovenitti P 2003 A generic algorithm for part orientation system for complex parts in rapid prototyping. J. Mater. Process. Technol 139 pp 110 116.

12. Egorov I N 2010 Position-force control of robotic and mechatronic devices Vladimir State University Vladimir p 243.

13. Grechukhin, A.N., Anikutin, I.S., Byshkin, A.S Management of space orientation of the end effector of generation of geometry system fiveaxis manufacturing machinery for additive generation of geometry.. MATEC Web of Conferences.Volume 226, 7 November 2018, Article number 0100214th International Scientific-Technical Conference "Dynamic of Technical Systems", DTS 2018; Don State Technical UniversityRostov-on-Don; Russian Federation; 12 September 2018 to 14 September 2018; Code 141842.

14. Grechukhin, A.N., Kuts, V.V., Razumov, M.S Ways to reduce the error of additive methods of forming. MATEC Web of Conferences. Volume 226, 7 November 2018, Article number 0100214th International Scientific-Technical Conference "Dynamic of Technical Systems", DTS 2018; Don State Technical UniversityRostov-on-Don; Russian Federation; 12 September 2018 to 14 September 2018; Code 141842.

15. Calculation of the controlled parameters of the 6-coordinate robot in the process of additive forming of products. Grechukhin, A.N., Kuts, V.V., Razumov, M.S. (2019) Journal of Physics: Conference Series, 1210 (1), article № 012053. 